\title{
Oral health care for patients undergoing therapy for head and neck cancer in KwaZulu-Natal, South Africa - A qualitative study
}

SADJ August 2020, Vol. 75 No. 7 p353 - p361

BS Bauluck-Nujoo', S Singh ${ }^{2}$

\section{ABSTRACT}

\section{Background}

There is limited published evidence in KwaZulu-Natal on access to oral health care for patients undergoing cancer therapy in the head and neck region.

\section{Objectives}

This study aimed to assess patients' oral health-related perceptions, practices and needs during cancer therapy.

\section{Methods}

This was a descriptive case study. A semi-structured face-to-face interview was conducted with volunteers $(n=12)$ undergoing cancer therapy in head and neck region. Purposive sampling was used to select study participants who were recruited from a public tertiary central referral hospital in KwaZulu-Natal. A semi-structured interview was also conducted with the eThekwin district coordinator for oral health services to gain better insight into oral health service delivery for patients with special needs.

\section{Results}

The results indicated that oral health care in the sample population was not prioritised. Some of the emergent themes included: participants' knowledge and oral health self-care practices, support for participants to cope with head and neck cancer, barriers in accessing facilitybased oral health care (poor access to dental services, failure of the local clinic to provide appropriate care), lack of referral by oncology care practitioners for patients to access dental care, and existing gaps in oral health service delivery.

\section{Author affiliations:}

1. Bibi S Bauluck-Nujoo: BDS (SSR Medical College-University of Mauritius), M.MEDSc (UKZN), School of Health Sciences, University of KwaZulu-Natal, South Africa.

ORCID Number: 0000-0002-7157-5122

2. Shenuka. Singh: B.OH, M.Sc (Dent), PhD (UWC), PG Dip Heal Res Ethics (Stell), Associate Professor: Discipline of Dentistry, School of Health Sciences, University of KwaZulu-Natal, South Africa.

Corresponding author: Shenuka. Singh

Discipline of Dentistry, School of Health Sciences, University of

KwaZulu-Natal. Private Bag X54001, Durban, 4000.

Email: singhshen@ukzn.ac.za

Author contributions:

1. Bibi S Bauluck-Nujoo: First author - 70\%

2. Shenuka. Singh: Second author $-30 \%$
The reported non-existence of a specific oral health policy to address cancer and the absence of a risk factor intervention program highlighted some of the shortcomings for quality oral health service delivery in this population group.

\section{Conclusion}

The results indicated that oral health care is important for patients undergoing cancer therapy. There is an urgent need for oral health planning in the province to take into account the specific oral health needs of this vulnerable population.

\section{INTRODUCTION}

The increasing rate of cancer in the developing world, including the incidence of cancers located in the head and neck region, remains a huge public health concern.

Oral cancer ranks as the sixth most common cancer on a global level and third in developing nations, with a high age standardized mortality rate (ASMR) of 6.8 (per 100,000 persons per year).,.2 Similarly oesophageal cancer is ranked as the eighth leading cancer by the global cancer statistics database (GLOBOCAN) and accounted for $3.2 \%$ of new cases in $2018 .^{3}$

It is further postulated that probably 'two-thirds of oral and pharyngeal cancers (excluding nasopharynx)' occur in developing countries. ${ }^{2}$ Alarmingly these countries 'account for $67 \%$ of cancer-related deaths' yet only ' $5 \%$ of cancer-related spending' is evident in response to this public health crisis. ${ }^{4}$

The high cancer mortality rates in developing countries could be attributed to patients' late presentation for diagnosis and treatment, suboptimal access to health care services, or patients opting to seek traditional health care before attending a health care facility. ${ }^{1}$

Some of the possible reasons for delays in accessing the health system could include cultural beliefs that cancer "is a curse", poor socio-economic status, and challenges with availability of transport. ${ }^{5}$ These challenges complicate treatment outcomes and disease prognosis, which could in turn, place further strain on an overburdened health system. 
Given the disproportionate dependence on public oral health care in developing countries, it is inevitable that similar challenges would occur with patients presenting with head and neck cancer (HNC).

HNC collectively could include anatomical sub-sites such as the pharynx (including hypopharynx, nasopharynx and oropharynx), larynx, paranasal sinuses and nasal cavity, minor and major salivary glands, oral cavity (including lip, alveolar ridge, buccal mucosa, gingiva, tongue, retromolar trigone and floor of mouth), ear, skin, eye and in some instances, the brain..$^{6-12}$

However, there is no general consensus on this definition of HNC, given that the epidemiology, histopathology and aetiology of tumours vary in the head neck region. ${ }^{13}$ Conversely cancer incidence rates involving the lip, oral cavity and tongue, pharynx and larynx could be aggregated. ${ }^{14}$ The current reporting systems for HNC add to this complexity in that, databases could report cancer rates based only on the specific anatomical location.

More confusing, "terminologies such as oral cancer", "orofacial cancer", "oropharyngeal cancer", "head and neck cancer" have been used interchangeably' and this inconsistency in the 'nomenclature' complicates reporting on the epidemiology and burden of HNC. 1:478 One plausible way to overcome this impasse in defining and describing HNC would be through the use of rubrics developed by the International Classification of Disease (ICD-10) for oncology. ${ }^{15}$

Likewise the prevalence of HNC in South Africa and in other parts of Africa remains unclear due to a number of other complexities. These include under-reporting of cases in areas where there are poorly developed or non-existent cancer registries and inadequate health infrastructure. ${ }^{1}$ The current trends in HNC are alarming.

Adeola et al. used a cohort of 12 selected countries to illustrate HNC, oesophagus and Upper Aerodigestive Tract Cancer (UADTC) ranking. The authors concluded that South Africa was ranked fourth in the list for HNC and second for UADTC. ${ }^{1}$ Similarly a human papillomavirus (HPV) prevalence rate of $6.3 \%$ was recorded in a cohort of South African patients presenting with head and neck squamous cell carcinoma. ${ }^{16}$

According to data derived from the South African National Cancer Registry (SA-NCR) between 1996 and 2002, the average oral cancer ASIR (age standardized incidence rate) for males was 6.19/100,000/ per year and 1.60/100,000/per year for females in the country. About $6.2 \%$ of all non-skin cancers were registered as intra-oral and lip cancer in South Africa thus suggesting that these are arguably the most common HNC in South Africa. ${ }^{17,18}$

Another study using SA-NCR data (1988 until 2012) for oral, lip, oropharynx and nasopharynx cancer in South Africa showed a $30 \%$ decrease in intra-oral cancer rates for males (except Coloured men) and only a slight decline for lip cancer in males and intraoral cancer for females (except Black women).
The authors however added that registry data must be reviewed with caution given its variability and in some instances, unreliability. ${ }^{17}$ What remains clear is that HNC can be attributed to unhealthy lifestyle practices (poor dietary intake) and risky behaviours such as smoking, alcohol consumption, and sexual practices (that could contribute to HIV/HPV infections). ${ }^{1}$

The head and neck region is critical for basic functions such as chewing, swallowing, speech, breathing and hearing, thus cancers affecting this region will have an impact on individual quality of life. The common oral complications associated with $\mathrm{HNC}$ include oral mucositis, decreased salivary flow, taste disorders and pain. ${ }^{19-21}$ Patients have reported difficulty in eating, dysphagia (difficulty to swallow), odynophagia (painful swallowing), gustatory and auditory disturbances (due to oral mucositis and xerostomia), osteoradionecrosis, periodontal disease, trismus, hypersensitivity and recurring infections. ${ }^{19,22-26}$

Additionally around 58-97\% of patients diagnosed with cancer could require some form of dental treatment before cancer therapy. ${ }^{27}$ This necessitates the availability of appropriate oral health care to support patients through the journey of cancer diagnosis, treatment, post treatment and rehabilitation. Oral health-related management of the patient should commence prior to cancer therapy and then intensified during the treatment phase, thereafter ensuring post cancer treatment support. ${ }^{28,29}$

Despite the value and role that oral health services can play in contributing to improved oral health outcomes for patients with HNC, there is paucity of published evidence in this field. Similarly, there is limited publicly available evidence that oral health planning in KwaZuluNatal takes into account the specific oral health needs of patients with HNC.

To our knowledge, there is no published data that specifically explored HNC patients' perceived oral health needs and demand for oral health care in the province. This study thus aimed to assess perceptions of patients undergoing cancer therapy, their oral health practices, and the public oral health system's response to addressing care for patients with HNC.

\section{METHODS}

This was a descriptive case study using qualitative data to explore HNC patients' perspectives on oral health care. Studies using a qualitative approach are mainly concerned with observing patterns and trends in a data-set ('understanding the meaning') rather than quantifying the phenomenon being studied. ${ }^{30}$

Gatekeeper permission was obtained from KwaZulu-Natal Department of Health and ethical clearance was obtained from the University of KwaZulu-Natal (BREC Ref Number: BE 041/17). The study site was a public tertiary central referral hospital located in the eThekwini Metropolitan Municipality within the province of KwaZulu-Natal.

The study population comprised 12 voluntary participants 
$(n=12)$ undergoing active cancer therapy or attending follow-up sessions for maintenance therapy (patients in remission). Data saturation technique was used to determine the final study sample size. ${ }^{31}$

Volunteers were purposively selected from the waiting area in the Oncology unit. The study purpose was explained to all patients, and participants were only recruited after written informed consent was obtained from each interested person. A semi-structured face-to-face interview was set up, based on the willingness and availability of each participant.

Ethical considerations such as participant privacy, confidentiality and the right to withdraw from the study were discussed before the interview. The interview schedule comprised demographic questions related to the date of diagnosis, duration of treatment, present treatment regime, and lifestyle induced habits. Other open-ended questions included the participant's knowledge of oral health care in relation to overall well-being, oral health self-care practices, perceived barriers and opportunities to access oral health care, and availability of support to cope with the illness. An unoccupied room in the oncology department was used to conduct the interviews after prior arrangements were made with the oncology staff. This enhanced participants' privacy during the interview. The duration of the interview was 30 minutes.

Purposive sampling technique was used to set up another semi structured face-to-face interview with the oral health district coordinator in eThekwini Municipality. The interview schedule comprised questions related to oral health strategies in place to support patients with HNC and the extent to which oral health care covered in district health policy and planning. Other questions included existing institutional support for oral health promotion activities such as risk factor intervention programmes. The interview appointment and venue were based on the district coordinator's availability and convenience. The duration of the interview was 30 minutes. All interviews were audio-recorded.

For the data analysis process, the audio-recordings were first transcribed verbatim by a transcriber and a data clean-up process was applied. The narrative from each interview transcript was then coded and analyzed based on the conventional thematic analysis approach, described by Braun and Clarke. ${ }^{32}$

A code guide was developed to guide and support the coding process. Open nodes were generated in the open coding phase. This form of coding allows for inductive reasoning of the emergent themes. Inductive thematic saturation was used in data analysis process. This means that data analysis was concluded when no new codes or emergent themes could be derived from the collected data. ${ }^{33}$

Credibility was maintained by ensuring that the researcher had prior engagement with the research participants to build trust. Confirmability was maintained by doing an "audit trail" which took into consideration the pathway from data collection to data analysis. Transferability was ensured by providing a thick description of the data collection process, characteristics of participants and the data analysis process. Dependability was achieved through a clear description of the study methods and processes.

\section{RESULTS AND DISCUSSION}

Several themes were identified in this study: participants' knowledge and oral health self-care practices, support for participants to cope with HNC, barriers in accessing facility-based oral health care, lack of referral by oncology care practitioners for patients to access dental care, and existing gaps in oral health service delivery.

\begin{tabular}{|c|c|c|c|c|c|c|c|c|}
\hline \multirow{2}{*}{ Participants } & \multirow{2}{*}{$\begin{array}{l}\text { Date of } \\
\text { Diagnosis }\end{array}$} & \multirow{2}{*}{$\begin{array}{l}\text { Duration } \\
\text { of Treatment }\end{array}$} & \multicolumn{3}{|c|}{ Present Treatment Regime } & \multicolumn{3}{|c|}{ Past Habits and Duration } \\
\hline & & & Radiotherapy & Chemotherapy & Surgery & $\begin{array}{l}\text { Smoking } \\
\text { \& Duration } \\
\text { (Years) }\end{array}$ & $\begin{array}{c}\text { Alcohol } \\
\text { \& Duration (Years) }\end{array}$ & $\begin{array}{c}\text { Paan Chewing \& } \\
\text { Duration (Years) }\end{array}$ \\
\hline P1 & Oct-16 & 3 months & & $\sqrt{ }$ & & $\begin{array}{c}\sqrt{ } \\
18\end{array}$ & $\begin{array}{c}\sqrt{ } \\
10\end{array}$ & $x$ \\
\hline P2 & Oct-16 & 1 month & $\sqrt{ }$ & $\sqrt{ }$ & & $\mathrm{x}$ & $\mathrm{x}$ & $x$ \\
\hline P3 & 2013 & 30 days & $\sqrt{ }$ & & & $x$ & $x$ & $x$ \\
\hline P4 & Jan-17 & August & & $\sqrt{ }$ & & $\begin{array}{l}\sqrt{ } \\
-\end{array}$ & $\begin{array}{c}\sqrt{ } \\
\text { Occasional }\end{array}$ & $\mathrm{x}$ \\
\hline P5 & Jan-16 & 31 days & & $\sqrt{ }$ & & $x$ & $x$ & $x$ \\
\hline P6 & Apr-17 & 26 days & $\sqrt{ }$ & & & $\begin{array}{c}\sqrt{ } \\
10\end{array}$ & $\begin{array}{c}\sqrt{ } \\
\text { Occasional }\end{array}$ & $x$ \\
\hline P7 & Jun-15 & Not yet started & & & & $x$ & $\mathrm{x}$ & $\mathrm{x}$ \\
\hline P8 & Nov-16 & Does not know & & $\sqrt{ }$ & & $\begin{array}{l}\sqrt{ } \\
5\end{array}$ & $\begin{array}{c}\sqrt{ } \\
6-7\end{array}$ & $x$ \\
\hline P9 & 2014 & Forever & $\sqrt{ }$ & $\sqrt{ }$ & & $\begin{array}{c}\sqrt{ } \\
20\end{array}$ & $\begin{array}{l}\sqrt{ } \\
20\end{array}$ & $\begin{array}{c}\sqrt{ } \\
10\end{array}$ \\
\hline P10 & 2015 & Does not know & $\sqrt{ }$ & & & $x$ & $x$ & $x$ \\
\hline P11 & Nov-16 & Not been told & & & $\sqrt{ }$ & $x$ & $x$ & $\mathrm{x}$ \\
\hline P12 & Apr-16 & Does not know & $\sqrt{ }$ & $\sqrt{ }$ & & $\begin{array}{c}\sqrt{ } \\
15\end{array}$ & $\begin{array}{c}\sqrt{ } \\
10\end{array}$ & $x$ \\
\hline
\end{tabular}


The demographic profile of participants outlined in Table 1. The results indicated that almost half of the study participants had engaged previously in risky behavioural practices such as smoking and alcohol consumption.

\section{Theme 1: Participants' knowledge and oral health self-care practices}

Most participants indicated that oral health care was important for their overall well-being (Table 2). Participants also highlighted the important roles that key health care workers (including oral health workers) can play in creating awareness and support for optimal oral health care, as part of the clinical management for HNC.

Treatment for HNC could involve surgery, radiotherapy, chemotherapy and concurrent chemoradiotherapy. ${ }^{34-36}$ These multimodalities in the treatment of HNC could potentially impact on oral health status ${ }^{37}$ and influence individual quality of life. ${ }^{38,39}$ Dental health care workers are therefore critical in providing patient support and counselling in aspects related to healthy lifestyle practices and optimal oral health self-care. ${ }^{40}$

\section{Theme 2: Support for patients to cope with HNC}

This theme highlighted available support for study participants at a personal level. Most participants indicated receiving moral or financial support from family members. Moral support could contribute to better handling of psychological and physical challenges that patients face during diagnosis and clinical management of the health condition. ${ }^{41}$

Financial support is also important given the financial strain caused by loss of employment or time spent away from work. ${ }^{42}$ One interviewee highlighted the role of prayer as a form of spiritual support. This finding is supported by other studies that also conceded the value of prayer to help reduce anxiety and stress in patients with $\mathrm{HNC}$ and improve overall well-being. ${ }^{43,44}$

\section{Theme 3: Barriers to accessing oral health care}

Although participants recognized the importance of oral health care, the costs for purchasing oral health care products remained a challenge. Likewise some participants living in underdeveloped areas in Empangeni and Oakford outlined challenges in accessing facilitybased oral health care. This was possibly due to the reported limited availability of easily accessible public dental clinics or private dental surgeries in these areas (Table 3). This finding is consistent with other studies that highlight challenges in accessing oral health services can result in a greater burden of unmet oral health needs in socially and economically marginalised populations. ${ }^{45}$

Imbalances in oral health service delivery is a reality on multiple levels in South Africa. Imbalances occur in the skewed public-private distribution of oral health care workers and the urban-rural divide in the availability of public dental clinics. Public oral health services are in turn largely characterized by inequities in funding for oral health care, poor infrastructure and staff shortages



$\begin{aligned} & \text { Perceived knowledge of } \\ & \text { oral health: }\end{aligned}$
"Yes. The dentist said the health
of the mouth is important and to
"I think it is important that my
mouth must be clean so there are
no germs. The doctor explained
the benefits and complications
and told me about the side ef-
fects that there is going to be dry
mouth, dark skin, hair loss" (P3).

Table 3. Support for oral health care.

Familial Support

Responses

\section{A. Familial Support:}

How has your family supported you to obtain treatment?

1a. Lack of support

"Basically, I have been doing everything myself from the day I came out. I have been confident; I have been coming for treatment myself. I have no back up" (P9).

1b. Moral support

"They were supportive and tried to help. They are always there for me" (P7).

2. Financial Support

"They supported me a lot financially and caring for me" (P11).

"They give me money to see a doctor" (P12).

3. Telephonic conversation

"They support me by calling me asking me how I am doing" (P3).

4. Support through visit

"They come to visit" (P6).

5. Prayer and advice

"My family was also confused and they supported me through prayer and advice" (P8).

"That is why sometimes I get stressed. I am not smoking. I am not drinking why I get the cancer. I am going to church so why does the bad things go through to my life" (P10).

"They were supportive and tried to help. They are always there for me" (P7). 
(including lack of appropriate skills-mix to meet the needs of local communities). ${ }^{46}$ An adequate workforce is critical for delivery of quality oral health care given that almost $80 \%$ of the South African population are dependent on public oral health services. ${ }^{47}$

These resource linked shortages inevitably impacts on the availability and consequently, the quality of facilitybased oral health care. ${ }^{45}$ Poor investments in public oral health services can be traced back to poor policy decisions, especially when oral health priorities remains low on the health policy agenda.

These collective challenges will ultimately impact on disadvantaged communities' access to oral health services (Figure 1) and their subsequent utilization of these services. There is thus an urgent need to review health policy priorities such that the quality and access to oral health care can be improved. One possible way would be to explore public-private partnerships in oral health

care, so as to increase access in facility-based oral health care for vulnerable populations.

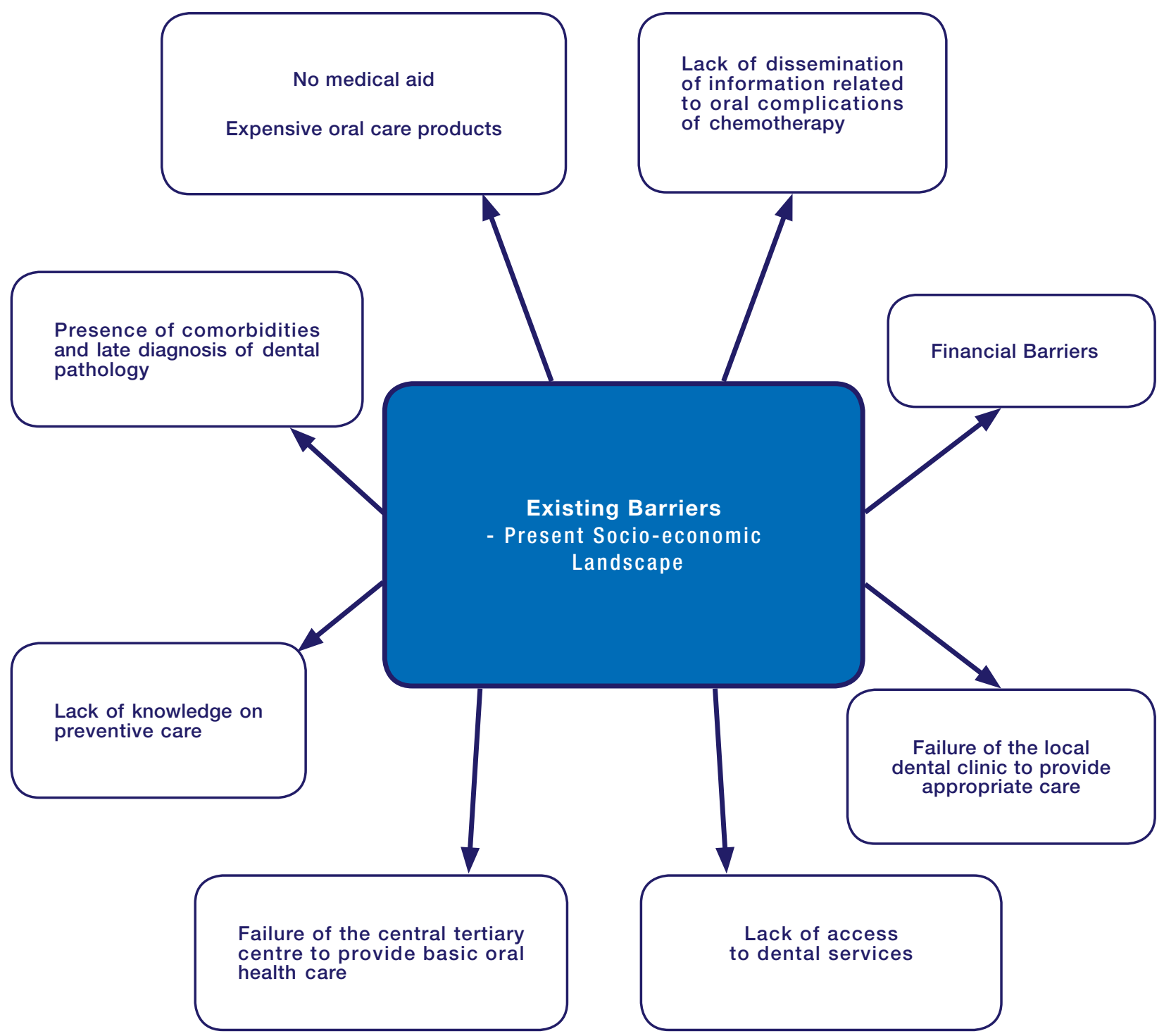

The perceived lack of referral by oncology doctors for patients to access oral health care was seen as an additional barrier. This shortcoming is supported Lawrence et al. who pointed out that medical practitioners might not recognize the value of dental assessment and oral health care in this population group. ${ }^{20}$ Another perceived barrier was inadequate dissemination of information related to oral complications of chemotherapy by oncologists and nurses.

This finding is consistent with Abed et al. who reported that patients felt that they received inadequate preparatory information on oral health related side-effects of treatment related to $\mathrm{HNC} .{ }^{48} \mathrm{Pai}$ and Ongole also reported that nurses working with cancer patients had inadequate oral health-related knowledge for patient management. ${ }^{49}$

There is need for continuous inter-professional evidencebased oral health care education 49 to ensure that oral health related information is consistent and readily avai- lable to patients with $\mathrm{HNC}$. 
Participants in this study also highlighted challenges in accessing oral health care due to existing co-morbidities. The co-existence of diseases such as hypertension, diabetes, obesity and bone loss could complicate care and health outcomes for patients with HNC. Oral health care becomes a low priority in the presence of other health conditions requiring urgent attention. This finding is supported by a study conducted in North Carolina where patients with oral complications experienced poor emotional and physical health outcomes compared to those with no oral health-related issues. ${ }^{50}$

\section{Theme 4: Gaps in oral health service delivery}

The interview with the district health coordinator suggested that oral health strategies remain isolated from general health interventions, as indicated in the following quotation:

We do not have a separate policy on oral health care for head and neck cancer patients. I have not seen one specifically for head and neck patients. But we got a specific policy in KZN to decrease the filling to extraction ratio (Oral health district coordinator).

From an oral health service delivery perspective, the district coordinator indicated that support was available for patients. This included identification of suspicious lesions during routine clinical examinations, oral health counselling and motivation to reduce risky behavioural practices such as smoking and alcohol consumption, and referral pathways for further clinical management.

However, a gap was identified in the availability of lifestyle induced risk-related intervention programmes:

We do not have any (risk factor intervention program) but we do encourage all our patients not to smoke and drink (Oral health district coordinator).

A risk factor intervention program is important to address common risk factors for non-communicable diseases (in this case head and neck cancer) as part of health determinants. ${ }^{51}$ The Common Risk Factor Approach creates an opportunity for oral health promotion to be incorporated into general health care. This approach is supported by the South African Oral Health Promotion framework. ${ }^{51}$

Education addressing the impact of tobacco smoking, alcohol consumption, areca nut-chewing and other risk factors should form part of an appropriately structured oral health promotion programme. ${ }^{52}$ A community level educational campaign and dedicated homebased care could be more beneficial, if properly implemented. ${ }^{52}$

Additional staff and resources could improve the quality of oral health care offered by the health system. This reiterates the need for a multidisciplinary team approach that includes oral health care workers for the comprehensive management of HNC.

Thus, oral health care should be the combined responsibility of all role-players in the multidisciplinary team for managing patients with cancer.

\section{Table 4. Existing barriers to oral health care}

Barriers at individual level

Responses

Do you experience any difficulty to buy stuff to keep the mouth clean? Is it difficult for you to go to the dentist?

No medical aid and expensive oral products

Lack of dissemination of information related to oral complications of chemotherapy

Financial barrier

Failure of the local dental clinic to provide appropriate care

Lack of access to dental services

Failure of the central tertiary centre to provide basic oral health care

Presence of comorbidities and late diagnosis of dental pathology
"I did not have medical aid so they referred me. Yes I experience difficulty to buy stuff to keep the mouth clean because they are expensive" (P1).

"They didn't say anything at all about importance (of oral health); they didn't mention it could have an effect on the teeth" (P2).

"We do not receive things like toothpaste and toothbrushes, it is expensive because my dad collects a disability grant. It is a financial strain because he wears diapers and all that has to be bought with his pension money" (P4).

"Yes since I started this treatment I have difficulty because the money is getting short.

We are using R96,00 a day for transport. It is difficult. We cannot afford to go to the private dentist and doctors where you have to pay more than the government hospitals. Money, it is very expensive for us because we are no longer working" (P6).

"They see so many patients a day. After 12.00 , they do not take any more patients. If [you go to the clinic] after 12.00. you must come back the next day. They do not do most of things, they just do general extractions. So we have to go to private dental practitioners" (P4).

"There are no dentists around where I live. It is like one hour's drive" (P5).

"They see so many patients a day. After 12.00 , they do not take any more patients. If [you go to the clinic] after 12.00. you must come back the next day. They do not do most of things, they just do general extractions. So we have to go to private dental practitioners" (P4).

"I have chronic pancreatitis and I am diabetic. I do not know whyl am still losing weight. I am $50 \mathrm{kgs}$. I was $80 \mathrm{kgs}$. It took the hospital about one and a half years to find out that I have cancer. The operation was done within a month because it was that serious" (P9).

"Yes now, before it wasn't difficult to go to the dentist although it was not too near, but now not anymore because of weakness" (P6). 


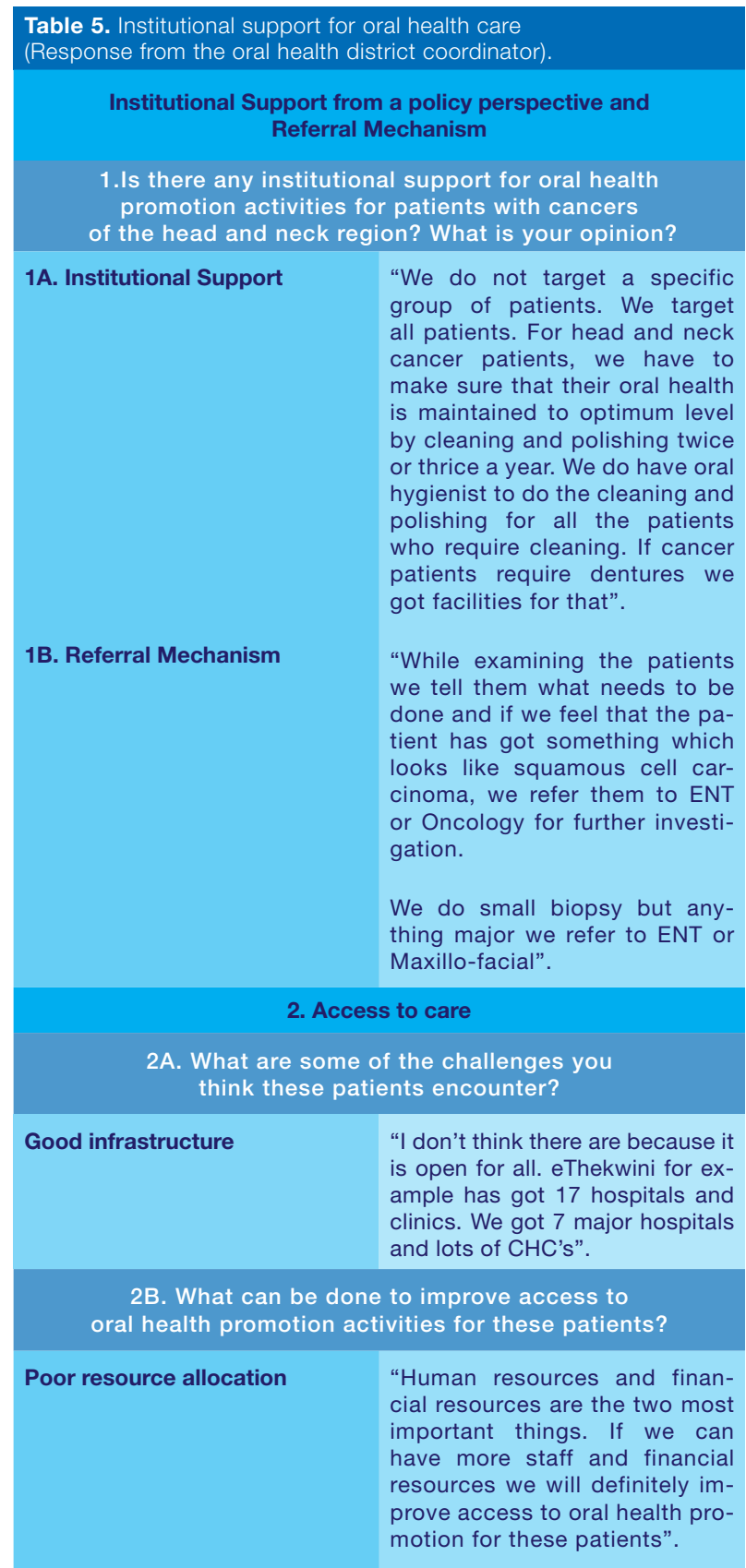

This finding is supported by $\mathrm{Mol}$ on the role of the health system, including oral health workers, to support patients diagnosed with cancer. ${ }^{53}$

Oral hygienists can also add value to a multidisciplinary team through the provision of preventive treatment plans tailored to individual patient needs. ${ }^{54}$

It is equally important that health interventions such as screening and early detection of cancer are incorporated into oral health service delivery. Early recognition of pre-malignant lesions through screening programs and population-based health education have shown to have favourable prognostic health outcomes. ${ }^{55}$

Thus there is need for appropriate training and skills transfer for oral health care workers (depending on the scope of practice) to screen, diagnose, refer or provide early interventions for premalignant and malignant lesions in the head and neck region. ${ }^{56}$
This requires continuing professional development in this area. ${ }^{57}$ It should be noted that support for oral health self-care practices should extend beyond the health system. Oral health care should be integrated into other key community-based activities such as support group programmes for people with cancer.

Strategies such as oral health education, tooth brushing and flossing techniques, as well as the availability of non-alcohol based mouth rinses should be integrated into general support programmes for people with cancer. ${ }^{40}$

Collectively these efforts can make significant contributions to improved quality of life for people with HNC. More research is needed to explore further opportunities to improve quality of life in people with HNC.

\section{Limitations of the study}

The study findings cannot be generalised. The study participants were drawn from a single site and the results cannot be extrapolated to other provinces and districts. Participants in this study were at different stages of treatment regimens.

A patient undergoing treatment could have a very different experience/knowledge of oral health care related to HNC compared to those starting with treatment. More research is required on newly diagnosed patients to assess their knowledge of oral health need at "day zero", that is, at the commencement of clinical management for HNC.

Nevertheless, this study provides valuable data on patient perspectives to oral health care. Future research in this area can be extended to other provinces in South Africa so as to obtain a national picture that could inform and influence oral health planning to meet the needs people affected by HNC.

\section{CONCLUSION}

The results indicate that support for oral health care is important for patients with HNC. There is an urgent need for oral health planning in the province to take into account the specific oral health needs of this vulnerable population.

\section{Acknowledgements}

Study participants for their generous contribution to this study.

\section{Declaration}

The authors declare no conflict of interest.

\section{Funding}

This paper forms part of a Masters dissertation for the first author. A scholarship of R25,000.00 was obtained from the College of Health Sciences, UKZN. 


\section{References}

1. Adeola $H$, Afrogheh A, Hille J. The burden of head and neck cancer in Africa: the status quo and research prospects. South African Dent J. 2018; 73(8): 3-5, https://doi. org/10.17159/2519-0105/2018/v73no8a1.

2. Warnakulasuriya S. Global epidemiology of oral and oropharyngeal cancer. Oral Oncol. 2009; 45(4-5) 309-16, https://doi. org/10.1016/j.oraloncology.2008.06.002.

3. Globocan Cancer Today - World Glob. Cancer Obs. 2019

4. Farmer P, Frenk J, Knaul FM, et al. Expansion of cancer care and control in countries of low and middle income: A call to action. Lancet. 2010; 376(9747): 1186-93. https://doi. org/10.1016/S0140-6736(10)61152-X.

5. Joshi P, Dutta S, Chaturvedi P, Nair S. Head and Neck Cancers in Developing Countries. Rambam Maimonides Med J. 2014; 5((2):e0009): 1-6. https://doi.org/10.5041/ RMMJ.10143.

6. World Health Organization. Pathology and Genetics of Head and Neck Tumours. 2005.

7. Argiris A, Karamouzis MV, Raben D, Ferris RL. Head and neck cancer. Lancet. 2008; 371: 1695-709, https://doi.org/ 10.1016/S0140-6736(08)60728-X

8. Chen YJ, Chang JTC, Liao CT, et al. Head and neck cancer in the betel quid chewing area: Recent advances in molecular carcinogenesis. Cancer Sci. 2008; 99(8): 1507-14, https://doi. org/10.1111/j.1349-7006.2008.00863.x.

9. Ouyang $\mathrm{Y}-\mathrm{H}$. Skin Cancer of the Head and Neck. Semin Plast Surg. 2010; 24(2): 117-26, https://doi.org/10.1055/s0030-1255329.

10. Romesser PB, Riaz N, Ho AL, Wong RJ, Lee NY. Cancer of the Head and Neck. 2012; 1037-70, https://doi.org/ 310.1016/B978-1-4557-2865-7.00068-0.

11. Erovic BM, Goldstein DP, Kim D, et al. Sebaceous gland carcinoma of the head and neck: The Princess Margaret Hospital experience. Head Neck. 2013; 35(3): 316-20, https://doi.org/10.1002/hed.22964.

12. Rettig EM, D'Souza G. Epidemiology of Head and Neck Cancer. Surg Oncol. Clin N Am. 2015; 24(3): 379-96, https://doi.org/10.1016/j.soc.2015.03.001.

13. Stewart B, Kleihues P. Human cancers by organ site World Cancer Rep. 2003; 232.

14. Korir A, Okerosi N, Ronoh V, Mutuma G, Parkin M. Incidence of cancer in Nairobi, Kenya (2004-2008). Int J Cancer. 2015; 137 : 2053-59, https://doi.org/10.1002/ijc.29674.

15. Glick M, Johnson MW. Oral and oropharyngeal cancer: What are the next steps? J Am Dent Assoc. 2011; 142(8): 892-94, https://doi.org/10.14219/jada.archive.2011.0280.

16. Sekee TR, Burt FJ, Goedhals D, Goedhals J, Munsamy Y, \& Seedat RY. Human Papillomavirus in Head and Neck Squamous Cell Carcinomas in a South African Cohort. Papillomavirus Res. 2018; 6: 58-62, https://doi.org/10.10 16/j.pvr.2018.10.006

17. Hille J, Johnson NW. The burden of oral cancer in subSaharan Africa. Transl Res Oral Oncol. 2017; 2: 1-13. https:// doi.org/10.1177/2057178x17721094

18. Ayo-Yusuf O, Lalloo R, Johnson N. Trends and ethnic disparities in oral and oro-pharyngeal cancers in South Africa (1992-2001). South African Dent J. 2013; 68(4): 168-73.

19. Jawad $H$, Hodson NA, Nixon PJ. A review of dental treatment of head and neck cancer patients, before, during and after radiotherapy: part 1. Br Dent J. 2015; 218(2): 65-8, https://doi.org/10.1038/sj.bdj.2015.28.

20. Lawrence M, Aleid W, McKechnie A. Access to dental services for head and neck cancer patients. $\mathrm{Br} J$ Oral Maxillofac Surg. 2013; 51(5): 404-7, https://doi.org/10.1016/j.bjoms. 2012.10.004.

21. Matsuzaki H, Tanaka-Matsuzaki K, Miyazaki F, et al. The role of dentistry other than oral care in patients undergoing radiotherapy for head and neck cancer. Jpn Dent Sci Rev. 2017; 53(2): 46-52, https://doi.org/10.1016/j.jdsr.2016.09.003.
22. Schultz C, Goffi-Gomez MVS, Liberman PHP, Pellizzon AC de A, Carvalho AL. Hearing Loss and Complaint in Patients With Head and Neck Cancer Treated With Radiotherapy Arch Otolaryngol Head Neck Surg. 2010; 136(11): 1065-9, https:// doi.org/10.1001/archoto.2010.180.

23. Frydrych A, Slack-Smith L, Park J, Smith A. Expertise Regarding Dental Management of Oral Cancer Patients Receiving Radiation Therapy Among Western Australian Dentists. Open Dent J. 2012; 6: 197-207, https://doi.org/10.2174/1874 210601206010197

24. McCaul L. Oral and dental management for head and neck cancer patients treated by chemotherapy and radiotherapy Dent Updat. 2012; 39(2): 135-8,140.

25. Mawardi H., Al-Mohaya M., Treister N. Oral health considerations in cancer survivors Saudi Med J. 2013; 34(5): 461-9.

26. Hartnett E. Integrating oral health throughout cancer care. Clin J Oncol Nurs. 2015; 19(5): 615-9, https://doi.org/10.11 88/15.CJON.615-619.

27. Bertl K, Loidl S, Kotowski U, et al. Oral health status and dental care behaviours of head and neck cancer patients: a cross-sectional study in an Austrian tertiary hospital. Clin Oral Investig. 2016; 20(6): 1317-27, https://doi.org/10.1007/ s00784-015-1618-x.

28. Mainali A, Sumanth K, Ongole R, Denny C. Dental consultation in patients planned for/undergoing/post radiation therapy for head and neck cancers: A questionnaire-based survey. Indian J Dent Res. 2011. https://doi.org/10.4103/ 0970-9290.93454.

29. Murphy BA, Deng J. Advances in Supportive Care for Late Effects of Head and Neck Cancer. J Clin Oncol. 2015; 33(29): 3314-21. https://doi.org/10.1200/JCO.2015.61.3836.

30. Turato ER. Qualitative and quantitative methods in health: Definitions, differences and research subjects. Rev Saude Publica. 2005; 39(3): 507-14, https://doi.org/10.1590/s003489102005000300025

31. Guest G, Bunce A, Johnson L. How Many Interviews Are Enough?: An Experiment with Data Saturation and Variability Field methods. 2006; 18(1): 59-82, https://doi.org/10.1177/ 1525822 X05279903.

32. Braun V, Clarke V. Using thematic analysis in psychology Qual Res Psychol. 2006; 3:2: 77-101, https://doi.org/http://dx.doi. org/10.1191/1478088706qp063oa.

33. Saunders B, Sim J, Kingstone T, et al. Saturation in qualitative research: exploring its conceptualization and operationalization Qual Quant. 2017; 1893-907, https://doi.org/10.1007/ s11135-017-0574-8.

34. Cognetti DM, Weber RS, Lai SY. Head and Neck Cancer: An Evolving Treatment Paradigm Cancer. 2008; 113(70): 1911-32, https://doi.org/10.1002/cncr.23654.

35. Tulunay-Ugur OE, McClinton C, Young Z, et al. Functional Outcomes of Chemoradiation in Patients with Head and Neck Cancer. Otolaryngol Neck Surg. 2013; 148(1): 64-8, https://doi.org/10.1177/0194599812459325.

36. Varelas X, Kukuruzinska MA. Head and neck cancer: From research to therapy and cure. Ann NY Acad Sci. 2014; 1333: 1-32. https://doi.org/10.1111/nyas.12613.

37. Pateman KA, Ford PJ, Batstone MD, Farah CS. Coping with an altered mouth and perceived supportive care needs following head and neck cancer treatment. Support Care Cancer 2015; 23(8): 2365-73, https://doi.org/10.1007/s00520-0152607-y.

38. Sheiham A. Oral health, general health and quality of life. Bull World Health Organ. 2005; 83(9): 644.

39. Bueno AC, Ferreira RC, Cota LOM, et al. Comparison of different criteria for periodontitis case definition in head and neck cancer individuals. Support Care Cancer. 2015; 23(9): 2599-604, https://doi.org/10.1007/s00520-015-2618-8.

40. Samim F, Epstein JB, Zumsteg ZS, Ho AS, Barasch A. Oral and dental health in head and neck cancer survivors. Cancers Head Neck. 2016. https://doi.org/10.1186/s41199016-0015-8 
41. O'Brien KM, Timmons A, Butow $\mathrm{P}$, et al. Associations between neighbourhood support and financial burden with un met needs of head and neck cancer survivors. Oral Oncol. 2017; 65: 57-64. https://doi.org/10.1016/j.oraloncology.2016. 12.019.

42. Zaidi AA, Ansari TZ, Khan A. The financial burden of cancer: Estimates from patients undergoing cancer care in a tertiary care hospital. Int J Equity Health. 2012; 11: 60, https://doi. org/http://doi.org/10.1186/1475-9276-11-60.

43. Mesquita AC, Chaves ÉDCL, Avelino CCV, et al. The use of religious/spiritual coping among patients with cancer under going chemotherapy treatment. Rev Latino-Am Enferm. 2013; 21(2): 539-45, https://doi.org/10.1590/S0104-11692013000200010

44. Carvalho CC, Chaves E de CL, lunes DH, et al. Effectiveness of prayer in reducing anxiety in cancer patients. Rev da Esc Enferm da USP. 2014; 48(4): 684-90, https://doi.org/https:// dx.doi.org/10.1590/S0080-623420140000400016.

45. Ramphoma KJ. Oral Health in South Africa: Exploring the role of dental public health specialists. South African Dent J. 2016; 71(9): 402-3.

46. Singh S, Myburgh NG, Lalloo R. Policy analysis of oral health promotion in South Africa. Glob Health Promot. 2010; 17(1): 16-24. https://doi.org/10.1177/1757975909356631.

47. Bhayat A, Chikte U. The changing demographic profile of dentists and dental specialists in South Africa: 2002-2015. Int Dent J. 2017; 1-6, https://doi.org/10.1111/idj.12332.

48. Abed H, Reilly D, Burke M, Daly B. Patients with head and neck cancers' oral health knowledge, oral health-related quality of life, oral health status, and adherence to advice on discharge to primary dental care: A prospective observational study. Spec Care Dent. 2019; 39(6): 593-602. https://doi.org/10.1111/scd.12418.

49. Pai R, Ongole R. Nurses' Knowledge and Education about Oral Care of Cancer Patients Undergoing Chemotherapy and Radiation Therapy. Indian J Palliat Care. 2015; 21(2): 225-30, https://doi.org/10.4103/0973-1075.156507.

50. Ingram SS, Seo PH, Sloane R, et al. The association between oral health and general health and quality of life in older male cancer patients. J Am Geriatr Soc. 2005; 53(9): 1504-9, https://doi.org/10.1111/j.1532-5415.2005.53452.x.

51. Molete MP, Daly B, Hlungwani TM. Oral health promotion in Gauteng: a qualitative study. Glob Health Promot. 2013; 20(1) 50-8, https://doi.org/10.1177/1757975913476906.

52. Nemoto R, Victorino A, Pessoa G, et al. Oral cancer preventive campaigns: Are we reaching the real target? Braz $J$ Otorhinolaryngol. 2015; 81(1): 44-9, https://doi.org/10.1016/j. bjorl.2014.03.002.

53. Mol RP. The role of dentist in palliative care team. Indian $\mathrm{J}$ Palliat Care. 2010; 16(2): 74-8. https://doi.org/10.4103/09731075.68408

54. Yi Mohammadi J, Franks K, Hines S. Effectiveness of professional oral health care intervention on the oral health of residents with dementia in residential aged care facilities: a systematic review protocol. JBI Database Syst Rev. Implement Reports. 2015; 13(10): 110-22, https://doi.org/10.111 24/jbisrir-2015-2330.

55. Dionne KR, Warnakulasuriya S, Zain RB, Cheong SC. Potentially malignant disorders of the oral cavity: Current practice and future directions in the clinic and laboratory. Int $\mathrm{J}$ Cancer. 2015; 136: 503-15, https://doi.org/10.1002/ijc.28754.

56. Petersen PE. World Health Organization global policy for improvement of oral health - World Health Assembly 2007. Int Dent J. 2008; 58: 115-21. doi:10.1111/j.1875-595X.2008.tb 00185.x, https://doi.org/10.1922/IDJ_1930Petersen07.

57. Hertrampf K, Wenz HJ, Koller M, et al. Assessing dentists' knowledge about oral cancer: Translation and linguistic validation of a standardized questionnaire from American English into German. Oral Oncol. 2009; 45(10): 877-82, https://doi. org/10.1016/j.oraloncology.2009.02.010. 